\title{
Sistemas de creencias parentales y orientación cultural en niños y niñas en cuidado transitorio: estudio de caso en una aldea gubernamental en Costa Rica
}

\section{Parental Belief Systems and Cultural Orientation in Children in Temporary Care: a Case Study in a State-Run Village in Costa Rica}

\author{
Esteban Durán-Delgado y \\ Universidad de Costa Rica, Costa Rica
}

\author{
Mariano Rosabal-Coto \\ Instituto de Investigaciones Psicológicas, \\ Universidad de Costa Rica, Costa Rica
}

\begin{abstract}
Resumen
En este artículo se presentan y discuten los hallazgos del estudio "Caracterización del estilo de crianza de los niños y las niñas en cuidado permanente en una Aldea Gubernamental: sistemas de creencias parentales y orientación cultural" (Durán-Delgado, 2012). La especificidad cultural del parentaje, en un contexto de cuidado en una institución de protección transitoria gubernamental, se analiza desde estudios precedentes sobre particularidad cultural del parentaje en Costa Rica. Se discute cómo el contexto y la cultura tienen una función homogenizante en lo que a trayectorias del desarrollo se refiere. A partir de una aproximación metodológica sensible al contexto y un diseño mixto, se trabajó en una institución de protección transitoria gubernamental. Se aplicaron entrevistas, escalas y observación etnográfica a niños, niñas y cuidadoras. A partir del estudio, se concluye que a pesar de la discontinuidad que el contexto institucional de cuidado ofrece, las trayectorias del desarrollo orientadas a la relacionalidad autónoma, propias de la cultura, son exitosamente estimuladas y concretadas. Las creencias y las prácticas de las cuidadoras muestran evidencia de una particularidad de un contexto institucional de cuidado, así como también no dejan de inscribirse en las trayectorias de la cultura local predominante. El estímulo a formas más autónomas del desarrollo en medio de un contexto de la relacionalidad refleja la necesidad de estimular formas resilientes para esta población en particular.

Palabras clave: Psicología cultural del desarrollo, parentaje y crianza en contextos institucionales, sistemas creencias parentales, orientación cultural y desarrollo infantil, institución de protección transitoria gubernamental, cuidado institucional, hogares transitorios de cuidado.
\end{abstract}

Esteban Durán-Delgado, Universidad de Costa Rica, Costa Rica; Mariano Rosabal-Coto, Instituto de Investigaciones Psicológicas, Universidad de Costa Rica, Costa Rica.

La correspondencia en relación con este artículo se dirige a Esteban Durán-Delgado, Universidad de Costa Rica. Dirección electrónica: estebanduran.psicologia@gmail.com 


\begin{abstract}
This paper discusses the findings of the study "Characterization of Parenting Style among Children in a PermanentCare State-Run Village: Parental Belief Systems and Cultural Orientation” (Duran-Delgado, 2012). The cultural specificity of parenting, in a context of institutional care in a semi-permanent publicly-run establishment is analyzed from the perspective of prior studies on the cultural peculiarities of parenting in Costa Rica. We discuss how the context and the culture have a homogenizing function with regards to trajectories for development. Based on a mixed-design context-sensitive methodological approach, we worked in a publicly-run institution for transitory care. Interviews, scales and ethnographic observation were carried out on the children and their care-takers. Based on the study, we conclude that in spite of the discontinuity offered by the institutional context, developmental trajectories oriented to the autonomous relationships typical of the culture are successfully stimulated and formed. The care-takers' beliefs and practices show evidence of a peculiarity of the institutional context of care, as well as not allowing them to enlist in the trajectories of the predominant local culture. The stimulus towards more autonomous forms of development in the midst of the context of the relationships reflects the need for stimulating more resilient forms for this population in particular.
\end{abstract}

Keywords: Developmental cultural psychology, parenting and child rearing in institutional contexts, parental belief systems, cultural orientation and child development; non-kinship homes, temporary governmental institutional care.

El presente estudio se ocupa del análisis de las continuidades y las discontinuidades entre el contexto de crianza constituido por una institución de cuidado gubernamental en Costa Rica, el contexto y la cultura local y nacional que le acoge. Para ello, por medio de un abordaje metodológico multimétodo y multifásico, que incluyó el estudio de las condiciones físicas de la institución de cuidado, la psicología de las cuidadoras y las pautas de interacción entre ellas, los niños, las niñas y el personal administrativo, se procuró responder a la siguiente interrogante: de qué manera los estilos de crianza y cuidado identificados en contextos familiares se correspondían o no en contextos de cuidado institucionales.

Se pretende, así, aportar a la discusión de los mecanismos de transmisión y evolución de la cultura, al ser el parentaje uno de sus principales vehículos a través de la promoción de formas de constitución del sí-mismo. Se asume como premisa que dichos mecanismos no son ajenos a los contextos de desarrollo diferentes a la familia y, por tanto, resultan susceptibles de estudio.

Esta discusión se inscribe en una línea de investigación de la psicología cultural del desarrollo desde abordajes culturalmente sensibles (Cole, 2002). Antecedentes internacionales (Kärtner, Borke, Maasmeier, Keller, \& Kleis, 2011; Keller et al., 2004), tanto como nacionales (Rosabal-Coto, 2004, 2012), han abordado temáticas relativas a dos grandes áreas del desarrollo, a saber: las metas de socialización y las prácticas parentales en la crianza (c.f. concepto de parentaje en Rosabal-Coto, 2012). En la evidencia local se ha mostrado la orientación cultural costarricense como propia las culturas de la relacionalidad (Keller \& Kärtner, 2013; Rosabal-Coto, 2012). Con el afán de ampliar el foco de estudio a contextos de desarrollo no tradicionales del parentaje, se han desarrollado estudios en poblaciones con 
enfermedades genéticas (Hemofilia) por Rodríguez (2010), enfermedades psiquiátricas (Salgado, 2014), niños con cáncer (Zamora, 2016), así como en zona rural (Elizondo \& Peña, 2014).

Desde la tradición de los modelos ecoculturales del desarrollo o desde la psicología cultural (Keller, 2007; Lonner, \& Adamopoulos, 1997; Whiting \& Whiting, 1975), se establece un importante vínculo entre la sociodemografía y el parentaje, que identifica cómo los factores contextuales influencian los valores y las normas parentales, a la vez que promueven conductas parentales informadas (Kärtner et al., 2011).

Dentro de este universo, se adopta como uno de los referentes básicos la propuesta de Keller (2000, 2002; Keller \& Kärtner, 2013) del Modelo Componencial del Parentaje. En dicha propuesta, se entiende el parentaje como el vehículo de la socialización y, como tal, se identifica como la interfase entre lo biológico y lo cultural. Las prácticas específicas responden a demandas ambientales, consensos sociales e ideas, y posibilidades de desarrollo a partir de la base biológica del individuo. Estos procesos adquieren su particularidad, según la correspondencia con el contexto, que, su vez, fungen como parte del complejo mecanismo de transmisión, perpetuación y transformación de la cultura.

La cultura, su desarrollo e inmersión está relacionada con la capacidad de producir y transmitir prácticas y significados compartidos con otros. La infancia y la niñez representan períodos en los que existe la mayor predisposición y capacidad para desarrollar destrezas ambientales, que habiliten para el desempeño en una cultura (Keller \& Kärtner, 2013). En este ámbito, se entiende que las estrategias parentales constituyen un repertorio de conductas intuitivas (como programas epigenéticos de respuesta al medio) (Keller, 2007), mediante las cuales los infantes y los niños son introducidos a sus mundos (Keller \& Kärtner, 2013). Al dar respuestas culturalmente mediadas según cada contexto, las figuras parentales dan soluciones culturales a tareas universales del desarrollo (universal developmental tasks) de cualquier ser humano (Keller \& Otto, 2011).

Esta línea de investigación define como necesidades básicas de desarrollo la autonomía y la relacionalidad, resueltas de forma particular según los contextos culturales (Keller, 2016). Keller las remite a los conceptos o atributos acuñados por Triandis (citado por Keller, 2016) de idocentrismo y alocentrismo. Ambos se relacionan de forma ortogonal entre sí; el primero describe el énfasis en la autoconfianza, la competencia, la unicidad, el hedonismo y la distancia emocional hacia otros y el segundo se remite al énfasis a la interdependencia, la socialibilidad y relaciones cercanas a otros. Estas dimensiones son retomadas por Kağitçibaşi $(2005,2007)$ en su Modelo de Cambio Familiar.

Un movimiento básico en la ecología familiar, que redunda en cambios en las orientaciones al idiocentrismo o alocentrismo, es aquel generado por el cambio de sociedades agrícolas tradicionales hacia la modernización, así como por efectos de la migración y aún más, específicamente, los efectos del incremento en la escolaridad. En el modelo de Kağitçibaşi (2007), los componentes de agencia y la distancia interpersonal son los identificables con la definición de Triandis. La agencia (agency) viene a ser definida en un continuum entre la autonomía y la heteronomía, mientras que la distancia interpersonal (interpersonal distance), oscila entre la distancia y la proximidad.

Con el fin de integrar y ampliar la capacidad explicativa de estos aportes, Keller (2016) propone un modelo contextual del desarrollo que identifica en las culturas su forma de resolver las necesidades de autonomía y relacionalidad. Las culturas de proximidad y las culturas de relacionalidad (Keller \& 
Kärtner, 2013) evocan trayectorias del desarrollo que tienden a identificarse como predominantes en ciertos contextos específicos, no por la geografía, sino por la correspondencia con condiciones socioculturales, socioeconómicas, como sociodemográficas; es decir, reflejan un cambio adaptativo resultante de los procesos de globalización y desarrollo socioeconómico. Asimismo, muestran claras tendencias en patrones de estructura familiar y consecuentemente reflejan también sus particularidades en lo relativo a metas de socialización y estilos parentales, así como en orientaciones culturales del self(Keller, 2003).

Las culturas distales o autónomas tienden a predominar en contextos altamente urbanizados con ciertos niveles de escolaridad, industrializados y basados en economías de acumulación y mercado, mientras tanto las culturas proximales están vinculadas con contextos más tradicionales, de base agrícola, rural, con bajos niveles de escolaridad. Los procesos de transición entre ambos modelos ocurren durante la migración de lo rural a lo urbano, hacia otros países, así como cuando se dan cambios significativos en el aumento de la escolaridad. Estos procesos, en sus efectos, se pueden homologar a la aculturación que sufren migrantes rurales de países en desarrollo, hacia contextos occidentales industrializados (Kağitçibaşi, 2005).

Tanto Kağitçibaşi (2007) como Keller (2003) reconocen un modelo que refleja estos contextos de transición, denominado relacional-autónomo. Este tiene como rasgo que tanto la relacionalidad como la autonomía mantienen el mismo grado de importancia, aunque con niveles de variabilidad incluso dentro de una misma cultura (Keller \& Lamm, 2007).

En estudios locales se ha confirmado evidencia de dichas trayectorias del desarrollo. Rosabal-Coto (2004) propone que el estilo de parentaje culturalmente particular y de predominio en el contexto costarricense es la orientación a la autonomía-relacional, a pesar de que muestra variabilidad intracultural entre zona rural y urbana. Entre otros factores, se asocia con diferencias en nivel socioeconómico y la escolaridad. Esto confirma diferencias en metas de socialización más orientadas a la autonomía ya determinadas en estudios precedentes (Leyendecker, Lamb, Schölmerich, \& Miranda, 1997). En un estudio con muestras rurales costarricenses, Elizondo y Peña (2014) también lo corroboran.

Los procesos de cambio social se reflejan en todas las dimensiones involucradas en el desarrollo de las personas. Greenfield (2009) propuso un modelo de cambio social estableciendo una relación directa en la sociodemografía de los grupos humanos con dimensiones como los valores sociales, modelos económicos y prácticas de crianza. Aún más, se encuentra plena coincidencia en la propuesta de Keller (2007), de los ambientes de aprendizaje y el desarrollo temprano descritos en su Modelo Componencial del Parentaje.

A partir de las propuestas de Greenfield (2009), Keller (2016) y Kağitçibaşi (2007), podemos establecer una serie de confluencias que logran constituir un modelo de comprensión del desarrollo, sus particularidades contextuales y las trayectorias específicas, que pueden tomar medios culturales determinados. Estos medios culturales o cultural mileu según Keller y Kärtner (2013) dan asiento a entornos socioculturales, que, en un continuum, expresan las culturas proximales y las culturas distales. Esta tradición logra incorporar y concretar los conceptos de Markus y Kitayama (1991) relativos al desarrollo del self en relación con las trayectorias del desarrollo del niño. 


\section{Trayectorias de la socialización del self infantil}

\section{a) Contextos proximales}

Las etnoteorías parentales y sus respectivas prácticas constituyen un modelo de infancia en el que se asientan diversas trayectorias al desarrollo del self infantil (Keller, 2016).

Como ya se mencionó, las culturas de la relacionalidad se encuentran asociadas a modelos socioeconómicos tradicionales, agrícolas, más propios de contextos rurales, en los que la media de escolaridad tiende a ser menor de 7 años. Sus entornos de aprendizaje estimulan en los niños un self organizado a partir de la pertenencia social, el sentido de grupalidad (en caso de nuestro contexto, con una fuerte tendencia al familismo) (ver Elizondo \& Peña, 2014; Rosabal, 2012). Las concepciones de infancia se basan en una orientación a la jerarquía, heterónomos, en que la figura adulta promueve la filiación jerárquica. El sentido del sí mismo se asienta fuertemente en el desarrollo de una relacionalidad psicológica y emocional. Se favorece el hecho de que en las relaciones con otros medie fuertemente la noción del self (Kağitçibaşi, 2007; Keller, 2003, 2007; Seidl-de-Moura,Cruz de Carvalho, \& Viera, 2013).

También, se han identificado metas de socialización con marcada tendencia a la relacionalidad que muestra variabilidad en grupos urbanos frente a rurales (Rodríguez, 2010; Durán-Delgado, 2012). Existe una coocurrencia con etnoteorías parentales que reflejan también un repertorio de expectativas y metas de socialización con una fuerte orientación a valores sociales propios de la relacionalidad jerárquica. Valores tales como respeto, simpatía y obediencia tienden a mantenerse como los más apreciados por las figuras parentales costarricenses (Álvarez, Brenes, \& Cabezas, 1990; Rosabal-Coto, 2004). Además, la misma evidencia se ha encontrado en etnoteorías parentales en Guatemala (García, Pauley, Gibbons, \& Ashdown, 2015). Su presencia es típica en contextos urbanos no occidentales (Greenfield, Keller, Fuligni, \& Maynard, 2003; Keller, 2016; Rübeling et al., 2011).

\section{b) Contextos distales}

Los contextos distales, propios de ambientes industrializados, sociedades occidentales con predominio de modelos económicos basados en el mercado, el comercio y la acumulación (Greenfield, 2009), son sociedades complejas y favorecen más altos niveles de escolaridad. Las concepciones sobre infancia promueven modelos centrados en el niño o niña, estimula significativamente el desarrollo de una conciencia de sí mismo y propenden el sentido de la autonomía como un rasgo predominante del self como agente independiente. Esto promueve un sentido del sí mismo asentado en la autonomía psicológica y esta como punto de referencia frente al entorno. El parentaje se asienta en modelos interactivos (parento-filiales) de interacción que estimulan, de forma muy temprana, la mentalización de estados, modelos de relación diádica exclusiva, cara a cara (Keller, 2007, 2014), así como el realce de los rasgos psicológicos individuales. Es altamente valorado y estimulado el logro individual, la autoexpresión y autorrealización a partir de sus etnoteorías (Abels, 2014; Keller, 2016; Otto \& Keller, 2014). Igualmente, se resalta que, en la misma línea de estudios, se ha venido corroborando que, dentro de un mismo contexto, existe una variabilidad intracultural (Kärtner et al., 2011; Keller \& Lamm, 2007; Rosabal-Coto, 2004). 


\section{Contexto cultural específico}

Una dimensión culturalmente relevante en la orientación cultural de la relacionalidad, en particular en contextos latinoamericanos, por consiguiente costarricense, es el familismo. Este rasgo se entiende como un fuerte sentido de pertenencia y definición del sí mismo a partir de la familia como primer grupo de referencia. Asimismo, se manifiesta en un fuerte sentido del deber y obligación hacia la familia. En estudios precedentes, tanto en muestras latinoamericanas (Calderón-Tena, Knight, \& Carlo, 2011; Sabogal, Marín, Otero-Sabogal, Vanoss \& Pérez-Stable, 1987; Steidel \& Contreras, 2003), como costarricenses (Elizondo \& Peña, 2014; Rodríguez, 2010; Rosabal-Coto, 2004) se ha reflejado tanto a nivel de valor y expectativa social, como dimensión interactiva importante. En los estudios han predominado mediciones actitudinales del alocentrismo familiar (Lay et al., 1998), pero tiende a coincidir con la dimensión estructural y conductual (Sabogal et al., 1987). Si bien no es una dimensión exclusiva en grupos latinoamericanos y puede mostrarse igualmente en otros contextos culturales, sigue siendo una dimensión culturalmente sensible (Schwartz, 2007). La fuerte presencia de este rasgo hace que, incluso, en contextos de inmigración, se mantenga constante y consistente con paso de las generaciones (Greenfield et al., 2003).

Resumiendo, a modo de un perfil del parentaje predominante en el contexto cultural costarricense, existe evidencia de una orientación al self relacional-autónomo (Kağitçibaşi, 2007; Rosabal Coto, 2012). Igualmente, destaca el familismo propio de una cultura proximal (Keller \& Kärtner, 2013). Tanto a nivel de etnoteorías, como de prácticas parentales, se promueven estilos que priman una relacionalidad jerárquica, coincidente con una disciplina heterónoma (Keller, 2016), que premia valores como el respeto, la obediencia, al niño "bien educado" (Moreno, 2003; Rosabal Coto, 2012).

\section{El reto del parentaje en contextos institucionales de cuidado}

La pertinencia de estudiar de forma sensible la infancia demanda entender contextos como los resultantes del abandono de las figuras parentales y las consecuentes respuestas institucionales, e.g. aquellas ofrecidas por el Estado. Estas soluciones de derecho no solo atienden a las necesidades específicas de protección, sino también se inscriben o salen de los parámetros y modelos de parentalidad predominantes en un contexto cultural específico. Estos contextos permiten conocer la continuidad o la discontinuidad del desarrollo ante condiciones en que los presupuestos normativos no se ordenan de acuerdo a la generalidad. Por tanto, ofrecen un interesante campo para explorar las respuestas que el medio puede dar a favor o en contra de los niños (Sroufe \& Waters, 1977).

Según reportes de United States Agency for International Development (USAIDS) y United Nations Children's Fund (UNICEF), se estima que existen en el mundo cerca de 153 millones de niños en todo el mundo en condición de vulnerabilidad y adversidad. Esto incluye aquellos niños en las calles, campos de refugiados, así como aquellos en condición de riesgo por tráfico para trata sexual o laboral, reclutados como soldados en conflictos armados e incluso separados de sus familias por desastres naturales. El porcentaje estimado de niños residentes en instituciones de cuidado es de aproximadamente 2 a 8 millones (McCall \& Groark, 2015).

El interés por niños en contextos institucionales de cuidado no es nuevo. Importantes sistematizaciones (McCall, van IJzendoorn, Juffer, Groark, \& Groza, 2011) de los efectos en el desarrollo han mostrado diferentes efectos en el desarrollo del momento y posterior. Estudios costarricenses, que abordan la 
experiencia infantil en instituciones de cuidado, discuten con marcada relevancia la dimensión afectiva con énfasis en la experiencia de separación. Sugieren que las alternativas de cuidado no ofrecen las condiciones suficientes para el desarrollo integral de los niños (Durán-Delgado, 2012).

En un estudio de seguimiento a 313 niños, en hogares sustitutos por cuatro años, Bell et al. (2015) investigan trayectorias de desarrollo, conductas resultantes y prácticas parentales. También, buscan predictores de trayectorias de resiliencia. Si bien no se comprueba que el tipo de entrenamiento a los cuidadores influya en el desarrollo de los niños, los autores sugieren centrarse más en factores relacionados como las características de los cuidadores como mediadores de mayor impacto. Efectos tales como dificultad en el desarrollo de un apego seguro con las nuevas figuras parentales han sido señalados por Bell, Romano y Flynn (2015), así como efectos de retraso en el desarrollo motor, cognitivo y social (McCall et al., 2011). No obstante, se identifica la deprivación social y la alteración como una de las principales causas de malestar en el desarrollo posterior (Johnson \& Gunnar, 2011).

Diversos estudios sobre niños institucionalizados han sido consistentes al resaltar la importancia de la relación entre cuidadoras y el potencial de desarrollo a largo plazo de los niños. A pesar de que se ha reconocido que el internamiento en instituciones de cuidado temporal, como orfanatos, tienen un efecto negativo en cuanto a estimular retraso en el desarrollo y la capacidad de resiliencia (van IJzendoorn et al., 2011), se ha identificado que la calidad de la relación entre cuidadores institucionales está vinculada a un mejor pronóstico en el desarrollo de niños institucionalizados, como el efecto positivo en ellos, independientemente del contexto (McCall \& Groark, 2015). Capacidades como la resiliencia aún se identifican ligadas con diversas variables, en particular los ambientes afectivos, sea institucionales de transición o de adopción definitiva. Estos estudios muestran que, muchas veces, factores ligados a la calidad del vínculo tienen más poder explicativo que la formación de los cuidadores o las condiciones físicas o contextos institucionales (Bell et al., 2015). Aún más, el paso a familias temporales y/o adoptivas siempre significa un incremento significativo en el desarrollo al punto de lograrse reajustes en el desarrollo.

A la luz de este panorama, el presente estudio convoca los desarrollos teóricos y metodológicos de la psicología cultural del desarrollo para explorar las características de la crianza que sucede en una alternativa de cuidado estatal en Costa Rica. Específicamente, se pretende responder, ¿de qué manera los estilos de crianza identificados en contextos familiares se corresponden o no en contextos de cuidado institucionales? El estudio asume como hipótesis que:

Las prácticas de cuidado en el contexto institucional favorecen la interdependencia psicológica y la constitución de un sí-mismo autónomo relacional, en congruencia con hallazgos previos en Costa Rica para contextos familiares.

Que las cuidadoras se constituían como figuras relevantes para los niños y las niñas en tanto agentes encargadas del cuidado.

Se asume, como principal supuesto, que los mecanismos de transmisión y perpetuación de la cultura relativos a las prácticas de cuidado y el parentaje no son ajenos a los contextos de desarrollo diferentes a la familia y, por tanto, son susceptibles de estudio. 


\section{Método}

Se implementó un diseño metodológico en una institución de cuidado transitorio de personas menores de edad, desde un abordaje multimétodo (Triandis, 1988), entendido como una estructura secuencial y lógica de estrategias cuantitativas y cualitativas. Referentes a nivel nacional e internacional confirman el valor de este tipo de diseños (Carmiol, 2003; Kağitçibaşi, 2002; Keller et al., 2006; Mayseless, Scharf, \& Sholt, 2003; Rosabal-Coto, 2004), que permiten comparar, contrastar información y ajustar las metodologías a procesos en desarrollo para sensibilizarlas al fenómeno de estudio. Tomando como referencia el concepto de "nicho del desarrollo" (Harkness \& Super, 1986), se definieron tres grandes dimensiones de estudio: escenarios físicos y sociales, costumbres de cuidado, educación y psicología de los cuidadores. Asimismo, se establecieron dos niveles de análisis, a saber: el nivel normativo (relacionado con creencias, etnoteorías) y el nivel relacional (contextos de interacción, prácticas, etc.) de la crianza o parentaje (Kağitçibaşi, 2007). Dado los diferentes contextos y perfil de las y los participantes, se diseñaron y validaron diversos instrumentos que respondieran sensiblemente a los sujetos de estudio, a la vez que facilitaran información en cada una de esas dimensiones.

En la figura 1 se ilustra el diseño metodológico y la secuencia de aplicación de los instrumentos y las técnicas de recolección de información.

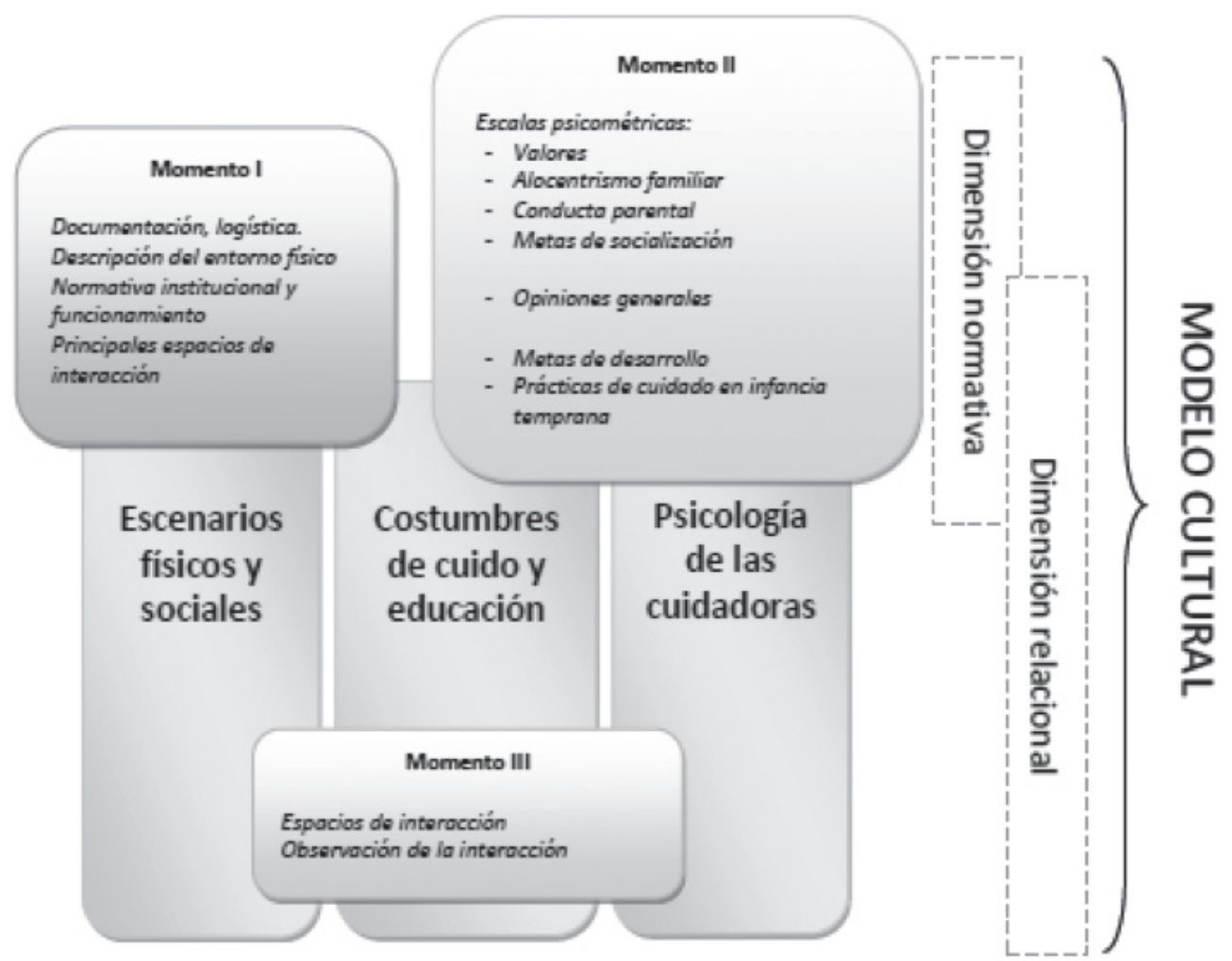

Figura 1. Diseño metodológico. (Fuente: Durán-Delgado, 2012). 
La complejidad del contexto demandó que las estrategias garantizaran la triangulación de datos (Flick, 2004), a partir de la convergencia y la confirmación de hallazgos. Esto requirió complementaridad y secuencialidad entre los resultados obtenidos por diferentes métodos.

\section{Participantes}

El estudio se realizó en la Aldea Arthur Gough del Patronato Nacional de la Infancia ${ }^{1}$, ubicada en la Gran Área Metropolitana de Costa Rica. Esta institución recibe niños y niñas que, luego de un proceso administrativo o judicial, son separados de manera temporal o definitiva de su familia ante la vulneración y/o la violación de sus derechos fundamentales.

Al momento de recolección de los datos, la institución contaba con una población atendida de 69 personas menores de edad (54.9\% hombres, $45.1 \%$ mujeres), con una edad promedio de 10 años y 9 meses; alojados en 8 casas con una ocupación promedio de 8.8 personas. La población atendida estaba distribuida en casas de acuerdo con criterios de edad, vínculo familiar o condición de discapacidad. La permanencia promedio de los menores en la Aldea era de 2 años y 9 meses. Un $46.5 \%$ de la población atendida presentaba algún tipo de discapacidad (leve o profunda), y un 1.4\% presentaba alguna enfermedad crónica. En el grupo trabajado no se contó con niños con alguna discapacidad o enfermedad crónica.

En cuanto al personal de cuidado directo, comúnmente denominadas “tías”, la Aldea contaba, al momento del estudio, con una planilla en propiedad de 15 cuidadoras. Todas fueron invitadas a participar en el estudio. La mayor proporción de participantes (9 casos) tenía 51 años de edad o más. En su mayoría provenía de comunidades fuera del Gran Área Metropolitana (12 casos). Todas las participantes se dedicaban a oficios "no calificados", previo a su ingreso a la Aldea, y la máxima escolaridad registrada fue de bachillerato universitario incompleto, en dos casos.

Tanto en el caso de las personas menores de edad, como de las cuidadoras, se firmaron los consentimientos y los asentimientos informados de rigor.

\section{Recolección de datos}

Los datos se recolectaron en el primer decenio del presente siglo. A continuación, en la tabla 1, se describe la metodología usada de acuerdo con el momento metodológico correspondiente:

\footnotetext{
${ }^{1}$ Institución pública del Estado costarricense. Fue fundada en 1930. Es la designada como el ente rector en encargada de las políticas y las acciones tendientes a la protección y atención de la niñez. Entre sus funciones está el estructurar, organizar y ejecutar el sistema de cuidado gubernamental. Este funciona a partir del modelo de "Aldea". Comprende varias casas integradas por aproximadamente 10 niños y niñas a cargo de una cuidadora adulta. La Aldea Arthur Gough fue fundada en 1972.
} 


\section{Tabla 1}

Descripción de la estrategia de recolección de datos.

\begin{tabular}{|c|c|c|c|}
\hline Momento metodológico & Instrumentos y métodos & Participantes & Recolección de datos \\
\hline Momento I & $\begin{array}{l}\text { Observación general } \\
\text { Modelo institucional } \\
\text { Normativa institucional }\end{array}$ & $\begin{array}{l}\text { Personal administrativo de } \\
\text { la Aldea }\end{array}$ & $\begin{array}{l}\text { Consultade documentación } \\
\text { en oficinas de la Aldea }\end{array}$ \\
\hline Momento II & $\begin{array}{l}\text { Escalas psicométricas y } \\
\text { cuestionarios }\end{array}$ & Cuidadoras & $\begin{array}{l}\text { Escalas y cuestionarios } \\
\text { auto administrados (tres } \\
\text { casos), y administrados } \\
\text { por el investigador (doce } \\
\text { casos) en una o dos sesiones } \\
\text { individuales de dos a tres } \\
\text { horas de duración. }\end{array}$ \\
\hline \multirow[t]{2}{*}{ Momento III } & Entrevista uso del espacio & Personas menores de edad & $\begin{array}{l}15 \text { niños, niñas y adolescentes } \\
\text { en edad escolar. Entrevista } \\
\text { aplicada en oficinas de la } \\
\text { Aldea }\end{array}$ \\
\hline & $\begin{array}{l}\text { Observación de la } \\
\text { interacción }\end{array}$ & $\begin{array}{l}\text { Personas menores de edad y } \\
\text { cuidadoras }\end{array}$ & $\begin{array}{l}\text { Observación de } 4 \text { casas } \\
\text { durante la cena a cargo de } \\
\text { un observador principal y } \\
\text { un observador asistente para } \\
\text { efectos de validez }\end{array}$ \\
\hline
\end{tabular}

Fuente: elaboración propia

\section{Descripción de los instrumentos utilizados}

Los instrumentos seleccionados respondieron a los requerimientos de información de cada momento metodológico. Tal como se mencionó, los momentos se estructuraron de manera secuencial con el fin de contrastar datos y enriquecer los métodos sobre la marcha a la luz de los resultados preliminares.

- Momento I

El primer momento del estudio correspondió a la dimensión "Espacios físicos y sociales" del nicho de desarrollo y consistió en investigación documental. Se sistematizaron datos sociodemográficos de la población atendida de la Aldea, del personal de cuidado directo, del modelo de atención y normativa interna.

- Momento II

Este momento correspondió mayormente a la dimensión "Psicología de las cuidadoras". Incluye, también, elementos de la dimensión "Costumbres de cuidado y educación". Se utilizaron los siguientes instrumentos (ver tabla 2): 


\section{Tabla 2.}

Instrumentos utilizados para la relección de datos del Momento II.

\begin{tabular}{|c|c|c|c|c|}
\hline Instrumento & Descripción general & Tipo de instrumento & Categorías de estudio & Tipo de análisis \\
\hline $\begin{array}{l}\text { Cuestionario de } \\
\text { valores (Keller et } \\
\text { al., 2004) }\end{array}$ & $\begin{array}{l}23 \text { preguntas de } \\
\text { selección, respuesta } \\
\text { breve y escalas } \\
\text { Likert }\end{array}$ & Cuestionario & $\begin{array}{l}\text { Valores relevantes en } \\
\text { el parentaje } \\
\text { Fuentes de } \\
\text { información y redes } \\
\text { de apoyo } \\
\text { Uso del tiempo libre }\end{array}$ & Cualitativo \\
\hline $\begin{array}{l}\text { Metas de } \\
\text { socialización } \\
\text { (Harwood, 1992) }\end{array}$ & 4 preguntas abiertas & Cuestionario & $\begin{array}{l}\text { Autorrealización, } \\
\text { autocontrol, amor, } \\
\text { decencia, conductas } \\
\text { apropiadas } \\
\text { misceláneas. }\end{array}$ & Cualitativo \\
\hline $\begin{array}{l}\text { Escala de conducta } \\
\text { parental (Van } \\
\text { Leween, 2000) }\end{array}$ & 45 ítemes tipo Likert & Escala psicométrica & $\begin{array}{l}\text { Pautas de interacción } \\
\text { entre niños y } \\
\text { cuidadores }\end{array}$ & $\begin{array}{l}\text { Estadística } \\
\text { descriptiva }\end{array}$ \\
\hline $\begin{array}{l}\text { Escala de familia } \\
\text { (Lay et al., 1998) }\end{array}$ & $\begin{array}{l}21 \text { ítemes tipo Likert } \\
(\alpha=.75)\end{array}$ & Escala psicométrica & $\begin{array}{l}\text { Grado de vinculación } \\
\text { con la familia }\end{array}$ & $\begin{array}{l}\text { Estadística } \\
\text { descriptiva, } \\
\text { correlaciones }\end{array}$ \\
\hline $\begin{array}{l}\text { Metas de desarrollo } \\
\text { (Keller et al., 2004) }\end{array}$ & $\begin{array}{l}18 \text { ítemes tipo } \\
\text { Likert organizados } \\
\text { en dos subescalas: } \\
\text { Automonía: ( } \alpha=.80 \\
\text { niño, } \alpha=.70 \text { niña) } \\
\text { Vinculación ( } \alpha=.83 \\
\text { niño, } \alpha=.80 \text { niña). }\end{array}$ & Escala psicométrica & $\begin{array}{l}\text { Grado de autonomía } \\
\text { y vinculación en el } \\
\text { parentaje de niños y } \\
\text { niñas }\end{array}$ & $\begin{array}{l}\text { Estadística } \\
\text { descriptiva, } \\
\text { correlaciones }\end{array}$ \\
\hline $\begin{array}{l}\text { Prácticas parentales } \\
\text { a los } 3 \text { meses de } \\
\text { edad (Keller et al., } \\
\text { 2004) }\end{array}$ & $\begin{array}{l}50 \text { ítemes tipo } \\
\text { Likert } \\
(\alpha=.77)\end{array}$ & Escala psicométrica & 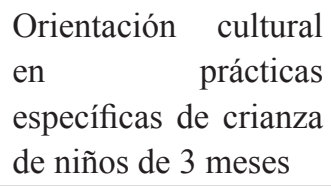 & $\begin{array}{l}\text { Estadis tica } \\
\text { descriptiva, } \\
\text { correlaciones }\end{array}$ \\
\hline
\end{tabular}


Tabla 2

Instrumentos utilizados para la relección de datos del Momento II.

\begin{tabular}{lllll}
\hline \multicolumn{1}{c}{ Instrumento } & Descripción general & Tipo de instrumento & Categorías de estudio & Tipo de análisis \\
\hline $\begin{array}{l}\text { Prácticas parentales } \\
\text { segundo y tercer año } \\
\text { de vida (Keller et }\end{array}$ & $\begin{array}{l}23 \text { ítemes tipo } \\
\text { Likert } 2004)\end{array}$ & Escala psicométrica & $\begin{array}{l}\text { Orientación cultural } \\
\text { en prácticas }\end{array}$ & $\begin{array}{l}\text { Estadística } \\
\text { descriptiva, }\end{array}$ \\
& & & $\begin{array}{l}\text { específicas de crianza } \\
\text { de niños de } 2 \text { y } 3 \text { años }\end{array}$ & correlaciones \\
$\begin{array}{l}\text { Opiniones generales } \\
\text { (Keller et al., 2004) }\end{array}$ & $\begin{array}{l}23 \text { ítemes tipo } \\
\text { Likert }\end{array}$ & Escala psicométrica & $\begin{array}{l}\text { Orientación cultural } \\
\text { en prácticas } \\
\text { específicas de crianza }\end{array}$ & $\begin{array}{l}\text { Estadística } \\
\text { descriptiva, } \\
\text { correlaciones }\end{array}$ \\
\hline
\end{tabular}

Fuente: elaboración propia

- $\quad$ Momento III

Para evaluar las categorías "Espacios físicos y sociales" y "Costumbres de cuidado y educación", se aplicó una entrevista a personas menores de edad atendidas por la Aldea y se diseñó un ejercicio de observación no participante.

Entrevista: consistió en un breve instrumento de elaboración propia, que se aplicó a una muestra de 15 niños/as, con el objetivo de definir qué espacios de la Aldea y las casas eran sus preferidos, así como sus principales usos y actividades. Se definió un "mapa social”, cuya configuración se utilizó para desarrollar la observación de la interacción.

Observación de la interacción: se desarrolló una guía de observación no participante a partir de los resultados obtenidos en los momentos metodológicos anteriores (Cohen, Stern, Balaban, Gropper, 2008). La observación fue de tipo no participante y se seleccionaron únicamente cuatro cuidadoras, denominadas "casos extremos"; es decir, las dos que obtuvieron los puntajes más altos y las dos que obtuvieron los puntajes más bajos en un índice elaborado con los resultados de las escalas de Familia (Lay et al., 1998) y Metas del Desarrollo (Keller et al., 2004).

La guía de observación se elaboró a partir de las categorías recomendadas por Rosabal-Coto (2007) en el Cuaderno Metodológico para la Investigación de la Interacción Madre-Infante, así como otras derivadas del Modelo de Componentes de Crianza (Keller, Voelker \& Zach, 1997; Keller, 2003; adaptaciones de Rosabal-Coto, 2004). Se agregaron elementos adicionales a partir del análisis del desempeño individual de las cuidadoras en cuestionarios y escalas.

En cuanto al espacio y la situación por observar, se seleccionaron a partir de los resultados de la entrevista a niños y niñas, sobre el uso del espacio y las actividades preferidas. La situación por observar fue la cena, celebrada en cada casa a las 5:00 p.m. (ver tabla 3). 
Tabla 3

Descripción de los componentes del ejercicio de observación.

\begin{tabular}{ll}
\hline \multicolumn{1}{c}{ Elementos a observar } & Elementos transversales de análisis \\
\hline Descripción de la situación: & Comunicación verbal - no verbal \\
$\begin{array}{l}\text { De qué se trata la situación y cómo se desenvuelve } \\
\text { Participantes: quiénes forman parte de la situación }\end{array}$ & Proximidad física \\
$\begin{array}{l}\text { Episodios: acciones o actividades con claro inicio y fin y un } \\
\text { objetivo claro }\end{array}$ & \\
$\begin{array}{l}\text { Roles: posición y función de cada participante en el espacio } \\
\text { social }\end{array}$ & Afectos asociados \\
\hline
\end{tabular}

Fuente: elaboración propia

\section{Resultados}

\section{Escenarios físicos y sociales}

Como nicho de desarrollo, la Aldea Arthur Gough combina características similares a las de una institución de cuidado y una casa de habitación. Cuenta con instalaciones equipadas, zonas verdes, seguridad continua, un modelo de atención y un equipo técnico interdisciplinario para la atención integral, que incluye encargadas de cuidado directo. Lo anterior plantea encuentros y desencuentros con los contextos tradicionales de crianza, al menos, a nivel nacional, que deben considerarse a la hora de interpretar los resultados.

Para los autores, el contexto institucional de crianza posee, en su dimensión normativa, características específicas que no tiene un contexto familiar tradicional, a saber: una jerarquía, una normativa institucional y directrices de carácter técnico. Este conjunto de normas dibujan un ámbito de acción determinado (en el sentido de restricciones o constraints según Poortinga \& Soudijn, 2002) para el quehacer de todo el personal de la Aldea, pero específicamente el de las encargadas de cuidado directo. Es en ese ámbito de acción en que este estudio se centra.

El accionar de las encargadas de cuidado directo se encuadra en ámbito establecido por las directrices institucionales y del equipo técnico de la Aldea. Sin embargo, son ellas las primeras responsables de la convivencia a lo interno de cada casa, rol que se hace más saliente cuando el personal técnico no está en las instalaciones de la Aldea al finalizar la jornada de trabajo y durante los fines de semana. Esta convergencia de lo público y lo privado de la dinámica de la Aldea impacta de manera singular las prácticas de parentaje de las encargadas de cuidado directo. ¿De qué manera lo hacen? Los siguientes resultados aspiran a demostrarlo.

\section{Psicología de las cuidadoras}

La tabla 4 resume los principales descriptivos de las escalas psicométricas utilizadas para estudiar la psicología de las cuidadoras. En todos los casos, se realizaron análisis estadísticos no paramétricos, debido al tamaño de la muestra. La Escala de Familia (Lay et al., 1998) y la Escala de Metas del Desarrollo 
fueron los instrumentos de referencia para valorar la orientación cultural y, por ende, el modelo cultural predominante en la muestra. Los instrumentos restantes, de este momento metodológico, se utilizaron para caracterizar, en mayor detalle, el modelo saliente.

Tabla 4

Medias, desviaciones estándar y varianzas de las escalas psicométricas utilizadas.

\begin{tabular}{lccc}
\hline \multicolumn{1}{c}{ Escala } & Media & Desviación estándar & Varianza \\
\hline Escala de familia & 84.5 & 12.1 & 149.3 \\
$\begin{array}{l}\text { Metas del desarrollo } \\
\text { Subescala autonomía niño }\end{array}$ & 60.0 & 26.2 & 686.4 \\
$\begin{array}{l}\text { Metas del desarrollo Subescala } \\
\text { vinculación niño }\end{array}$ & 62.4 & 27.6 & 761.4 \\
$\begin{array}{l}\text { Metas del desarrollo } \\
\text { Subescala autonomía niña }\end{array}$ & 46.7 & 25.5 & 647.7 \\
$\begin{array}{l}\text { Metas del desarrollo Subescala } \\
\text { vinculación niña }\end{array}$ & 44.8 & 31.0 & 961.8 \\
$\begin{array}{l}\text { Prácticas parentales a los 3 meses de } \\
\text { edad }\end{array}$ & 202.3 & 17.8 & 316.2 \\
$\begin{array}{l}\text { Prácticas parentales a los 2 y 3 años } \\
\text { de edad }\end{array}$ & 117.5 & 12.2 & 149.7 \\
\hline
\end{tabular}

Fuente: elaboración propia

Siguiendo la literatura y los resultados de los estudios afines realizados en el país (Álvarez et al., 1990; Carmiol, 2003; Miranda \& Rosabal-Coto, 1997; Rosabal-Coto; 2004), se manejó la hipótesis de que la orientación cultural y su consiguiente modelo de familia de la Aldea se aproximaría al identificado en contextos urbanos del país, a saber, de interdependiencia psicológica de orientación relacional-autónoma (Kağitçibaşi, 2005). En la figura 2 se muestran los resultados de las subescalas de autonomía y vinculación de la Escala de Metas del Desarrollo (Keller et al., 2004), prácticamente equivalentes, con algunas variaciones por género. 


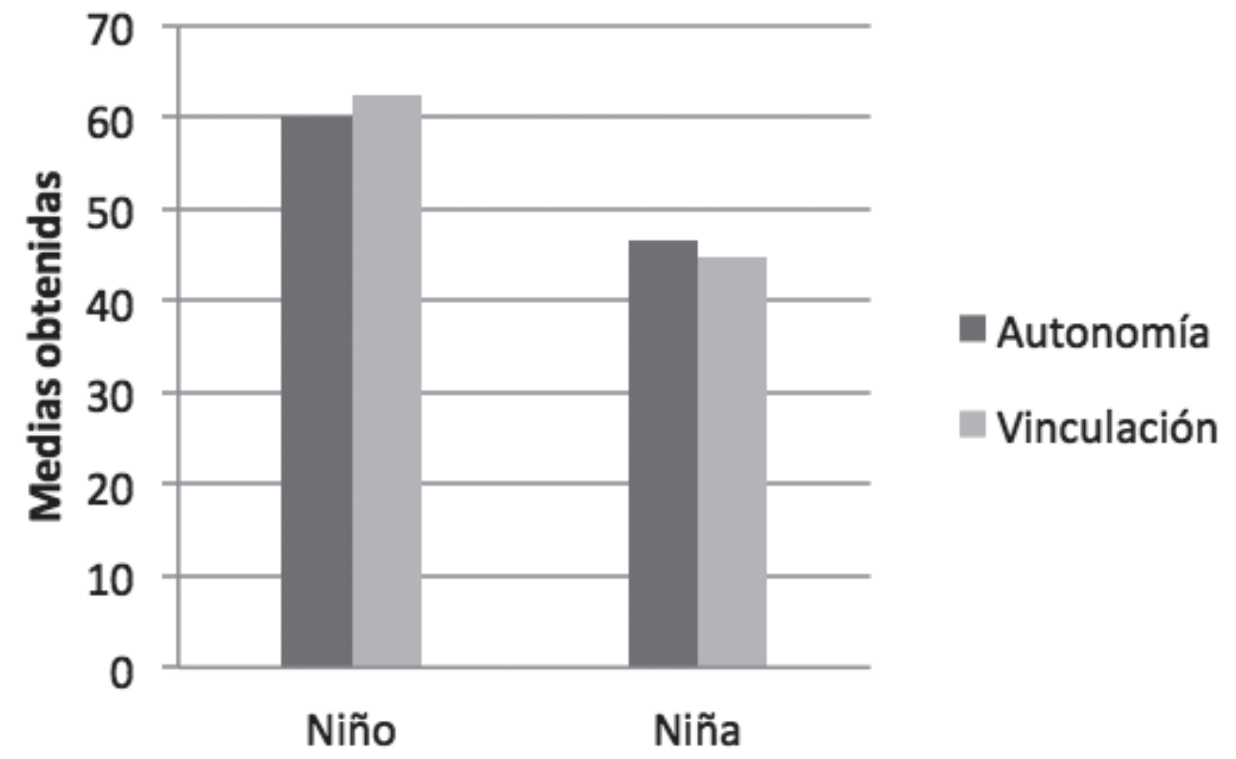

Figura 2. Comparación de medias, subescalas de autonomía y vinculación (niño y niña). Elaboración propia.

La coexistencia de rasgos de autonomía y vinculación es característica de países históricamente interdependientes, que han experimentado procesos de urbanización, industrialización y consecuente incremento en escolaridad, sobre todo a partir de la segunda mitad del siglo XX (Kağitçibaşi, 1996, 2007; ver también Keller et al., 2005; Keller, 2016; Keller \& Otto, 2011). Esto, lejos de impulsar los modelos de familia hacia la independencia exclusiva, se manifiesta en rasgos mixtos de que incluyen mayor agencia personal (autonomía) y proximidad psicológica (relacionalidad). Tal es el caso costarricense. A continuación, se describen los rasgos identificados en la muestra de este estudio para las dimensiones de valores morales y de convivencia, por un lado, y prácticas de crianza, por otro.

\section{Valores}

Al consultar a las cuidadoras por metas deseables y no deseables de desarrollo de las personas a su cargo, dos categorías obtuvieron mayor índice de respuesta: autorrealización y conductas apropiadas. La primera de estas categorías se asocia más con la autonomía y el logro personal, por la clara orientación al logro y la independencia y la segunda con la vinculación, la remitencia a la relacionalidad jerárquica por su énfasis en valores morales y de convivencia (Keller, 2016).

Específicamente, las cuidadoras mantienen la tendencia y destacan aquellos valores morales orientados tanto al logro personal (esfuerzo, perseverancia, disposición al trabajo y la responsabilidad), como a la convivencia (comunicación, respeto, ser servicial, buenos modales, amabilidad). Resultados similares se han obtenido en muestras costarricenses desde 1979 (ver Álvarez et al., 1990; Elizondo \& Peña, 2014; Miranda \& Rosabal-Coto, 1997, Rosabal-Coto; 2004; Zamora, 2016). 
El cuestionario de valores también permitió registrar cambios generacionales en las creencias de parentaje de la muestra, atribuidos al cambio cultural y educación. El más significativo se registró en el ámbito de la disciplina, pues todas las cuidadoras consultadas, a pesar de haberlo experimentado en su niñez, rechazan categóricamente el castigo físico como práctica disciplinaria y favorecen el diálogo y la reflexión como estrategia de resolución de conflictos. Se considera que la intervención de especialistas en ciencias sociales y de la salud que participan de los programas de capacitación de la Aldea, así como la normativa interna, juegan un rol fundamental en esta transformación.

\section{Prácticas}

Las escalas de Conducta Parental (Van Leeuwen, 2000; Van Leeuwen \& Vermulst, 2004), y las de prácticas parentales y opiniones generales de Keller et al. (2004), presentan un perfil actitudinal de las cuidadoras en su práctica del parentaje de los niños de la Aldea. Los resultados, que se presentan a continuación, se han consolidado en tres grandes categorías para efectos explicativos. Para una revisión detallada del Modelo de Componentes de Crianza, ver Keller, Voelker, \& Zach, 1997; y Keller, 2000, 2007.

Crianza positiva: todas las cuidadoras reportan alto grado de vinculación con la cotidianidad de los niños y niñas a su cargo. Denotan en el grado de proximidad, el flujo de comunicación y el intercambio de actividades de interés mutuo. En cuanto a los cuidados primarios, todas enfatizan la importancia de la salud y el bienestar de los niños, aspectos que se vigilan a través de la implementación de rutinas claramente definidas, particularmente importantes en el cuidado de los niños de menor edad. Simultáneamente, la mayoría de las cuidadoras considera fundamental que los niños se desenvuelvan de manera autónoma, tan pronto como sea posible, aspecto al que otorgan particular relevancia al tratarse de niños y niñas que viven en una institución de cuidado, y que, según su criterio, deben valerse por sí mismos desde temprana edad.

Además, las cuidadoras favorecen el contacto físico, mediado por la calidez, en su interacción con los niños. La gran mayoría de las participantes considera saludable este tipo de contacto para el desarrollo de las personas menores a su cargo. A su vez, ellas también consideran que la estimulación con objetos es útil y necesaria para el desarrollo cognitivo y motor de los niños e indican procurarlo.

Monitoreo y supervisión: las cuidadoras reportan el monitoreo como una actividad constante. Dicha supervisión es diferente de acuerdo con la edad del niño o de la niña: en niños pequeños está más asociada a la contingencia, y en niños mayores a la convivencia pacífica y el cumplimiento de las normas establecidas en cada casa y en la Aldea.

La mayoría de las cuidadoras reportan un elevado grado al atender, de manera inmediata, las señales negativas y el llanto de los niños. Aquellas señales, no necesariamente negativas, se atienden con menor inmediatez, y aquellas con mayor connotación positiva se responden en el mismo tenor la mayoría de veces posibles. A pesar de lo anterior, no todas las cuidadoras consideran que deban ser cálidas al responder adecuadamente a las señales de los niños a su cargo. Este rasgo, en particular, da cuenta de las variaciones de la muestra en relación con sus estilos de cuidado, más o menos proximales.

Disciplina: todas las cuidadoras reportan llamar la atención y castigar a los niños a su cargo, aunque indican ignorar, ocasionalmente, las conductas inapropiadas o no prescribir consecuencias. Cuando 
aplican castigos, la mayoría reportan utilizar la privación de beneficios y rechazan categóricamente el castigo físico. Las medidas disciplinares también incluyen el diálogo y la escucha empática, con el interés de que los niños y las niñas asuman sus responsabilidades tan pronto como puedan ser conscientes de ello. Estas prácticas se asocian más con una orientación a la autonomía, en tanto estimulan el autocontrol y la autorregulación.

\section{Tipologías como indicador de variabilidad en la muestra}

Con el fin de contar con un perfil claro de la distribución de la muestra en el continuo independencia-interdependencia, autonomía-relacionalidad, se consideró importante incluir una clasificación de "tipologías" de orientación cultural a partir de los resultados de la Escala de Familia (Lay et al., 1998). Tal como se ha observado hasta el momento, los datos indican resultados mixtos. Esto se traduce en cuidadoras distribuidas a lo largo del espectro. La tabla 5 describe dicha distribución según las tres tipologías seleccionadas. Como se puede observar, la mayoría de las cuidadoras se orientan más hacia el polo de la interdependencia, sin abandonar, claro está, creencias y prácticas asociadas con la autonomía.

Tabla 5

Tipologías a partir de la escala de familia.

\begin{tabular}{lcc}
\hline \multicolumn{1}{c}{ Tipo } & Frecuencia & Porcentaje \\
\hline Orientación a la Independencia & 2 & 13.3 \\
Mixta U autónoma relacional & 6 & 40.0 \\
Orientación a la Interdependencia & 7 & 46.7 \\
\hline
\end{tabular}

Fuente: elaboración propia

Para efectos metodológicos, esta distribución permitió seleccionar los casos "tipo" que se utilizaron para el tercer momento metodológico, que consistió en un ejercicio de observación no participante. Dado que no se consideró conveniente observar todas las casas de la Aldea, se prefirió seleccionar las dos cuidadoras con puntaciones más altas en la dimensión de independencia y las dos con puntuaciones más altas en la dimensión de interdependencia para estudiar, a nivel de la interacción, la expresión de su estilo particular de crianza. Los resultados de este ejercicio se presentan en el acápite siguiente.

\section{Pautas de interacción}

La tabla 6 resume los puntajes específicos de las cuidadoras seleccionadas para el ejercicio de observación de la interacción. Como situación por observar, se eligió la cena, celebrada en todas las casas a las 5:00 p.m., momento en que todos sus miembros están presentes, a saber: personas menores de edad, cuidadoras titulares y cuidadoras asistentes. 


\section{Tabla 6}

Medias en escalas y subescalas de casos seleccionados.

\begin{tabular}{lcccccc}
\hline & & Escala de Familia & \multicolumn{2}{c}{ Metas del desarrollo varón } & \multicolumn{2}{c}{ Metas del desarrollo mujer } \\
\multicolumn{1}{c}{ Caso } & & & Autonomía & Vinculación & Autonomía & Vinculación \\
\hline Extremo & 11 & 2.86 & 3.00 & 3.56 & 3.33 & 3.56 \\
Inferior & 6 & 3.48 & 2.89 & 3.11 & 2.89 & 3.11 \\
Extremo & 15 & 4.62 & 2.67 & 2.67 & 2.56 & 2.67 \\
Superior & 13 & 4.81 & 3.56 & 3.33 & 3.33 & 3.33 \\
\hline
\end{tabular}

Fuente: elaboración propia

Se elaboró un diseño y se validó mediante criterio de expertos, un protocolo de observación etnográfica para la interacción dada en contextos naturales. Como situación a observar, se eligió la cena, celebrada en todas las casas a las 5:00 p.m., momento en que todos sus miembros están presentes, a saber: personas menores de edad, cuidadoras titulares y cuidadoras asistentes. Se definieron cinco categorías de observación: descripción de la situación, participantes, episodios, roles y elementos transversales (comunicación verbal y no verbal, proximidad física y afectos asociados)

La tabla 7 resume los principales hallazgos de la observación. En el extremo de la independencia, una de las cuidadoras demostró un comportamiento con rasgos de heteronomía, caracterizado por marcada jerarquía, mayor distancia interpersonal y afecto negativo. Este resultó ser un caso único, pues la segunda cuidadora de esa dimensión mostró más cercanía física y afectiva, apertura al diálogo y calidez, conductas que podrían asociarse más bien a la interdependencia. 
Tabla 7.

Principales resultados de la observación.

\begin{tabular}{|c|c|c|c|c|}
\hline \multirow[t]{2}{*}{ Principales rasgos } & \multicolumn{2}{|c|}{ Cuidadoras con orientación a la autonomía } & \multicolumn{2}{|c|}{$\begin{array}{c}\text { Cuidadoras con orientación a la } \\
\text { interdependencia }\end{array}$} \\
\hline & Cuidadora 1 & Cuidadora 2 & Cuidadora 1 & Cuidadora 2 \\
\hline $\begin{array}{l}\text { Comunicación } \\
\text { verbal }\end{array}$ & $\begin{array}{l}\text { Órdenes y llamadas } \\
\text { de atención en tono } \\
\text { enfático }\end{array}$ & $\begin{array}{l}\text { Órdenes y llamadas } \\
\text { de atención en tono } \\
\text { cálido, también hay } \\
\text { diálogo }\end{array}$ & $\begin{array}{l}\text { Órdenes y llamadas } \\
\text { de atención en tono } \\
\text { enfático, también } \\
\text { diálogo en tono } \\
\text { cálido }\end{array}$ & $\begin{array}{l}\text { Tono tranquilo } \\
\text { y amable para } \\
\text { dirigirse a los niños } \\
\text { y compañeras }\end{array}$ \\
\hline $\begin{array}{l}\text { Comunicación no } \\
\text { verbal }\end{array}$ & $\begin{array}{l}\text { Rígida durante } \\
\text { las llamadas } \\
\text { de atención; } \\
\text { disposición cansada } \\
\text { el resto del tiempo }\end{array}$ & $\begin{array}{l}\text { Disposición relajada } \\
\text { durante toda la } \\
\text { situación }\end{array}$ & $\begin{array}{l}\text { Disposición relajada } \\
\text { durante toda la } \\
\text { situación }\end{array}$ & $\begin{array}{l}\text { Disposición relajada } \\
\text { durante toda la } \\
\text { situación }\end{array}$ \\
\hline Proximidad & $\begin{array}{l}\text { Distante, no procura } \\
\text { contacto }\end{array}$ & $\begin{array}{l}\text { Mantiene y } \\
\text { promueve contacto } \\
\text { con los niños, así } \\
\text { como expresión de } \\
\text { afecto }\end{array}$ & $\begin{array}{l}\text { Mantiene y } \\
\text { promueve contacto } \\
\text { con los niños, así } \\
\text { como expresión de } \\
\text { afecto }\end{array}$ & $\begin{array}{l}\text { Se muestra } \\
\text { accesible, mantiene } \\
\text { contacto con los } \\
\text { niños y la expresión } \\
\text { de afecto }\end{array}$ \\
\hline Tono afectivo & Enojo, cansancio & $\begin{array}{l}\text { Ecuánime, } \\
\text { demuestra afecto } \\
\text { positivo }\end{array}$ & $\begin{array}{l}\text { Ecuánime, } \\
\text { demuestra afecto } \\
\text { positivo }\end{array}$ & $\begin{array}{l}\text { Ecuánime, } \\
\text { demuestra afecto } \\
\text { positivo }\end{array}$ \\
\hline
\end{tabular}

Fuente: elaboración propia

En el otro extremo, las cuidadoras, con puntuaciones más altas en la dimensión de interdependencia, muestran conductas y prácticas asociadas al modelo cultural de la relacionalidad. Ambas dan señales de trato cálido hacia los niños, promueven el contacto físico y las demostraciones de afecto. Es importante destacar que estas cuidadoras demostraron un manejo más favorable del ambiente general de la casa, así como la disciplina de los niños a su cargo.

\section{Discusión}

La presente investigación aporta a una aproximación culturalmente sensible sobre el tema de creencias y prácticas del parentaje en un contexto costarricense, específicamente en el contexto de cuidado institucional. Por un lado, ofrece elementos teóricos y metodológicos válidos y aptos para ser aplicados en contextos culturales propios de la relacionalidad. Se logra evidenciar la pertinencia de aproximaciones metodológicas sensibles no solo al contexto particular de una cultura, sino también a sus variaciones. Se logra demostrar que, en pro de desarrollos cada vez más autóctonos y menos desde 
modelos etnocéntricos y WEIRD² (Henrich, Heine, \& Norenzayan, 2010, citado por Otto \& Keller, 2014), la investigación del desarrollo requiere modelos teóricos sensibles, así como de diseños metodológicos mixtos (Onwuegbuzie \& Leech, 2006).

Resultados de estudios anteriores se confirman en la presente investigación. Con respecto a la importancia de la familia, los resultados en la categoría de familismo, vinculación, y en sistemas de crianza vinculados con la interdependencia corroboran la importancia otorgada a los vínculos internos en el contexto costarricense (Triandis et al., 1986). La saliencia de otros elementos relacionados con la autonomía, sobre todo en la orientación al logro, el juego libre y el monitoreo ocasional, indican la coexistencia de rasgos mixtos u orientación al modelo de familia de interdependencia psicológica (Rosabal-Coto, 2004; Keller et al., 2005) o relacionalidad autónoma (Kağitçibaşi, 2007), lo cual es consistente con la primera hipótesis del estudio. Al respecto, se puede afirmar que la correspondencia con hallazgos anteriores en cuanto al contexto cultural, no se percibe una mayor discontinuidad en el contexto institucional transitorio de cuidado, sino que más bien hay continuidades claras con el contexto macro (estilo de parentaje de cada cuidadora, su interpretación de lo normativo y su forma de estructurar la cotidianidad de la casa).

Los contextos específicos demandan respuestas específicas. No obstante, el quehacer particular de los individuos también es un aporte fundamental. A través del contexto institucional, de cuidado bajo el modelo de Aldea, se muestra cómo la cultura no es una unidad estática (Keller, 2016), sino que logra funcionar articulando una mixtura de modelos propios entre una familia y una institución. Así, se responde ante el desarrollo normativo y se articulan alternativas ante la discontinuidad en el desarrollo. Se procuran recursos culturales personales y contextuales disponibles.

En el estilo de parentaje estudiado predomina el modelo de familia de interdependencia psicológica y, por lo tanto, se promueve la constitución de un sí mismo autónomo relacional (Kağitçibaşi, 2007). Diferencias internas se detectaron en la muestra respecto al grado de vinculación con la familia y la distancia interpersonal. Se considera que estas variaciones responden a las demandas de desarrollo dentro de la Aldea, bajo la premisa de que los niños y las niñas, que han sufrido privaciones de derechos y situaciones de violencia, deben desarrollarse más tempranamente como seres autónomos e independientes. No obstante lo anterior, la Aldea logra corresponderse con el estilo cultural predominante en el que la cercanía afectiva, a partir de un alto nivel de familismo, así como el énfasis en los valores vinculados con la comunicación, el respeto y la empatía, lo cual favorece la inserción de los niños para un mejor desempeño social, más allá de sus familias transitorias.

Con respecto a las metas de socialización, coinciden con resultados anteriores, entre las que destacan aquellas orientadas socialmente y se relacionan con la deseabilidad social (respetuoso/a, obediente, amable, honesto/a, que sea buena persona) (Rosabal-Coto, 2012). Diferencias previamente identificadas en relación con el nivel socioeconómico no pudieron ser contrastadas. Sin embargo, el presente estudio muestra una orientación a las expectativas basadas en el desarrollo de los niños, su salud y crecimiento, lo cual corresponde a estratos socioeconómicos medios y altos. Esto se explica a partir del nivel técnico de la información en cuidado y crianza de que las cuidadoras de la Aldea disponen.

\footnotetext{
${ }^{2}$ Acrónimo de white, educated, industrialized, rich, democratic. Blanco, educado, industrializado, rico y democrático como crítica a los modelos etnocéntricos occidentales.
} 


\section{Criterios de éxito de desarrollo}

El éxito a largo plazo del cuidado y la crianza en la Aldea puede resumirse en: ser buenas personas y contar con los suficientes recursos para salir adelante. En la cotidianidad, se observó que la obediencia es uno de los rasgos más enfatizados por las cuidadoras, así como la convivencia en orden.

En cuanto al repertorio de prácticas de cuidado y crianza, destaca la importancia que las cuidadoras atribuyen a la estructura de la rutina diaria y la regularidad de actividades relacionadas con los cuidados en salud, educación, descanso y ocio. Sin embargo, a pesar de este acento, la interacción exclusiva entre cuidadora y niños, por tiempo prolongado, no fue frecuente. Las cuidadoras, incluso cuando se dirigen a un niño o una niña, sea para llamar la atención o para comunicarse con él o ella, lo hace en la mayoría de las veces en referencia a una actividad grupal y son los niños y las niñas de mayor edad quienes mostraron mayor propensión a buscar el contacto exclusivo con las cuidadoras.

Además, sí aparece la calidez como condición de la afectividad en la interacción de niños y cuidadoras, aunque no de manera generalizada. De hecho, la distancia interpersonal entre cuidadoras y los niños guarda estrecha relación con el clima general de la casa, el estilo disciplinario, las pautas de comunicación y la expresión de afecto. Cuidadoras con mayor apertura y receptividad para la interacción con las niñas y los niños mostraron mayor facilidad para regular el clima de la casa. Estos hallazgos confirman la segunda hipótesis.

En concordancia con los hallazgos de Bell et al. (2015), en que se resalta la trascendencia de la calidad del vínculo de los cuidadores en instituciones de cuidado, este estudio muestra que la relevancia desde una cultura de la relacionalidad, favorecería e instrumentaría a los niños a partir del andamiaje relacional que la cultura ofrece mediante las cuidadoras (tías) de la Aldea.

En esa línea, un parentaje positivo, que muestra calidez y resalta el rasgo culturalmente específico de la relacionalidad (Keller, 2016), podría ser un factor positivo para el desarrollo de la resiliencia en niños y niñas en instituciones de cuidado. Estimular ciertos rasgos culturalmente específicos, como aquellos que fortalezcan vínculos y la calidad de estos, podrían llevar a mejores y más sanos ambientes en instituciones de cuidado estatales.

El modelo de Aldea, al parecer, podría mitigar los efectos negativos de orfanatos y/o albergues lo que parece coincidir con McCall et al. (2011) y McCall y Groark (2015), quienes constatan que los niños que experimentan interacción de calidad con las cuidadoras y sus mismos pares logran un mejor pronóstico en el desarrollo, que lo ofrecido por los típicos formatos institucionales.

Finalmente, el estudio del desarrollo humano en contexto requiere mayores avances para comprender el rol que juegan los contextos institucionales en este proceso. En el caso de las alternativas de protección, se requieren iniciativas de investigación que ayuden a eliminar los estigmas tradicionalmente asociados a estas instituciones, con el afán de mejorar las condiciones de vida de las personas quienes, en calidad de funcionarios o beneficiarios, participan de ese contexto común.

La Aldea es un espacio de restitución de derechos y las realidades que allí confluyen. Además, superan el alcance de lo que conocemos sobre la crianza en contexto en el país. Nuevos desarrollos podrán dar luz de abordajes innovadores que garanticen mayor acceso y ejercicio de derecho a las personas beneficiarias de estas instancias. 


\section{Referencias}

Abels, M. (2014, July). Infants' experiences and behaviors at nine months and their language development one year later in rural and urban Gujarat, India. In D. Matthews (President). SES differences in the language learning environments of infants raised in India, Mozambique, Turkey, the Netherlands and the UK. 13th International Congress for the Study of Child Language (IASCL), Amsterdam, Netherlands.

Álvarez, A., Brenes, A., \& Cabezas, M. (1990). Patrones de crianza en la familia costarricense. Actualidades en Psicología. Edición Especial. San José, Costa Rica: Instituto de Investigaciones Psicológicas, Universidad de Costa Rica.

Bell, T., Romano, E., \& Flynn, R. (2015). Profiles and predictors of behavioral resilience among children in child welfare. Child Abuse \& Neglect, 48, 92-103. http://dx.doi.org/10.1016/j.chiabu.2015.04.018

Calderón-Tena, C. O., Knight, G. P., \& Carlo, G. (2011). The socialization of prosocial behavioral tendencies among Mexican American adolescents: the role of familism values. Cultural Diversity and Ethnic Minority Psychology, 17(1), 98-106. doi: 10.1037/a0021825

Carmiol, A. (2003). La psicología cultural de la crianza: Un estudio sobre las concepciones de las madres (Tesis de licenciatura inédita). Universidad de Costa Rica, San José, Costa Rica.

Cohen, D. H., Stern, V., Balaban, N., \& Gropper, N. (2008). Observing and recording the behavior of young children. Nueva York, EE.UU.: Teachers College Press.

Cole, M. (2002). Culture and development. In H. Keller, Y. Poortinga, \& A. Scholmerich (Eds.), Between biology and culture. Perspectives on ontogenetic development (pp. 303-319). Cambridge, Reino Unido: Cambridge University Press.

de Carvalho, R. V. C., Seidl-de-Moura, M. L., Martins, G. D. F., \& Vieira, M. L. (2014). Culture and developmental trajectories: a discussion on contemporary theoretical models. Early Child Development and Care, 184(11), $1599-1614$.

Durán-Delgado, E. (2012). Caracterización del estilo de crianza de los niños y las niñas en cuido permanente en una Aldea Gubernamental: sistemas de creencias parentales y orientación cultural. (Tesis de licenciatura inédita). Universidad de Costa Rica, San José, Costa Rica.

Elizondo, R., \& Peña, M. (2014). Prácticas y Creencias Parentales en Madres Costarricenses pertenecientes a la Provincia de Guanacaste (Tesis de licenciatura inédita). Universidad de Costa Rica, San José, Costa Rica.

Flick, U. (2004). Introducción a la investigación cualitativa. Madrid: Morata.

García Egan, P., Pauley, D., Gibbons, J., \& Ashdown, B. (2015). Niños buenos vs niños malos: Etnoteorías de un Grupo de Madres Guatemaltecas. Revista Interamericana de Psicología, 48(2): 183-193.

Greenfield, P. M. (2009). Linking social change and developmental change: Shifting pathways of human development. Developmental Psychology, 45(2), 401-418.

Greenfield, P., Keller, H., Fuligni, A., \& Maynard, A. (2003). Cultural Pathways Through Universal Development. Annual Review of Psychology, 54, 461-90. doi: 10.1146/annurev.psych.54.101601.145221 
SISTEMA DE CREENCIAS PARENTALES Y ORIENTACIÓN CULTURAL EN NIÑOS Y NIÑAS

Harwood, R. (1992). The influence of culturally derived values on Anglo and Puerto Rican mother's perceptions of attachment behavior. Child Development, 63, 822-839.

Harkness, S., \& Super, C. (1986). The developmental niche: A conceptualization at the interface of child and culture. International Journal of Behavioural Development, 9(1), 545-569.

Johnson, D. E., \& Gunnar, M. R. (2011) Growth Failure in institutionalized children. Monographs of the Society for Research in Child Development, 76(4), 92-126.

Kağitçibaşi, C. (1996). Family and human development across cultures: A view from the other side. Hillsdale, EEUU: Lawrence Erlbaum Associates Inc.

Kağitçibaşi, C. (2002). A Model of Family Change in Cultural Context. Online Readings in Psychology and Culture. International Association for Cross-Cultural Psychology. Recuperado de https://scholarworks.gvsu.edu/cgi/ viewcontent.cgi? article $=1059 \&$ context $=$ orpc

Kağitçibaşi, C. (2005). Autonomy and relatedness in cultural context. Implications for self and family. Journal of Cross-cultural Psychology, 36(4), 403-422.

Kağitçibaşi, C. (2007). Family, self, and human development across cultures: theory and applications. Londres, Reino Unido: Lawrence Erlbaum Associates.

Kärtner, J., Borke, J., Maasmeier, K., Keller, H., \& Kleis, A. (2011). Sociocultural Influences on the Development of Self-Recognition and Self-Regulation in Costa Rican and Mexican Toddlers. Journal of Cognitive Education and Psychology, 10(1), 96-112. DOI: 10.1891/1945-8959.10.1.96

Keller, H., Voelker, S., \& Zach, U. (1997). Attachment in cultural context. Newsletter ISSBD, 1, 1-3.

Keller, H. (1997). Evolutionary approaches. En J. W. Berry, Y. Poortinga, \& J. Pandey (Eds.), Handbook of crosscultural psychology (2a. ed., Vol. 1, pp. 215-256). Needham Heights, Massachusetts: Allyn \& Bacon.

Keller, H. (2000). Human parent-child relationships from an evolutionary perspective. American Behavioral Scientist, 43(6), 957-969.

Keller, H. (2002). Development as the interface between biology and culture: a conceptualization of early ontogenetic experiences. En Keller, H., Poortinga, Y., \& Scholmerich, A. (Eds.), Between biology and culture. Perspectives on ontogenetic development (pp. 215-240). Cambridge, Reino Unido: Cambridge University Press.

Keller, H. (2003). Socialization for competence: Cultural models on infancy. Human Development, 46, 288-311.

Keller, H. (2007). Cultures of infancy. Mahwah, NJ: Lawrence Erlbaum Associates.

Keller, H., Lohaus, A., Kuensemueller, P., Abels, M., Yovsi, R., Voelker, S.,... Mohite, P. (2004). The bio-culture of parenting: Evidence from five cultural communities. Parenting: Science and Practice, 4,(1), 25-50.

Keller, H., Kuensemueller, P., Abels, M., Voelker, S., Yovsi, R., Jensen, H.,... Prerna, M. (2005). Parenting, culture, and development: A comparative study. San José, Costa Rica: Instituto de Investigaciones Psicológicas de la Universidad de Costa Rica. 
Keller, H., Lamm, B. (2007). Understanding Cultural Models of Parenting: The Role of Intracultural Variation and Response Style. Journal of Cross-cultural Psychology, 38(50), 50-57. DOI: 10.1177/0022022106295441

Keller, H. (2011). Autonomy and Relatedness Revisited: Cultural Manifestations of Universal Human Needs. Child Development Perspectives, 6(1), 1-7.

Keller, H., \& Otto, H. (2011). Different faces of autonomy. En X. Chen \& K.H. Rubin (Eds.), Socioemocional development in the cultural context (pp. 164-185). New York: Guilford Press.

Keller, H., \& Kärtner, J. (2013). Development: the cultural solution of universal developmental tasks. En M. Gelfand, C. Chiu, \& Y. Hong (Eds.), Advances in Culture and Psychology (pp. 63-116). New York, NY: Oxford University Press.

Keller, H. (2014). Introduction: Understanding relationships- what we would need to know to conceptualize attachment as the cultural solution of a universal developmental task. En: O. Hiltrud, \& Keller, H. (Eds.) The different faces of Attachment. Cultural variations on an Unversal Human Need (pp. 1-25). Cambridge University Press: Cambridge.

Keller, H. (2016). Psychological autonomy and hierarchical relatedness as organizers fo developmental pathways. Phil. Trans. R. Sco. B, 371: 20150070. http://dx.doi.org/10.1098/rstb.2015.0070

Lay, C., Fairlie, P., Jackson, S., Ricci, T., Eisenberg, J., Sato, T.,... Melamud, A. (1998). Domain-specific allocentrismidiocentrism: A measure of family connectedness. Journal of Cross-Cultural Psychology, 29(3), 434-460.

Leyendecker, B., Lamb, M., Schölmerich, A., \& Miranda, D. (1997). Contexts as moderators of observed interactions: A study of Costa Rican mothers and infants differing socioeconomic backgrounds. International Journal of Behavioral Development, 21(1), 15-34. doi: 10.1080/016502597384965

Lonner, W. J., \& Adamopoulos, J. (1997). Culture as antecedent to behavior. En J. W. Berry, Y. H. Poortinga, \& J. Pandey (Eds.). Handbook of cross-cultural psychology: Theory and Method (Vol. 1, pp. 43-83). Boston, EE.UU.: Allyn \& Bacon.

Markus, H., \& Kitayama, S. (1991). Culture and the self: Implications for cognition, emotion, and motivation. Psychological Review, 98(2), 224-253.

Mayseless, O., Scharf, M., \& Sholt, M. (2003). From Authoritative Parenting Practices to an Authoritarian Context: Exploring the Person-Environment Fit. Journal of Research on Adolescence, 13, 427-456. doi:10.1046/j.1532-7795.2003.01304002.x

McCall, R., van IJzendoorn, M., Juffer, F., Groark, C., \& Groza, V. (2011). Children without Permanent Parents: Research, Practice, and Policy. Monographs of the Society for Research in Child Development, 76(4), 1-318.

McCall, R., \& Groark, C. (2015). Research of institutionalized Children: Implications for International Child Welfare Practioners and Policymakers. International Perspectives in Psychology: Research, Practice, Consultation, 4(2), 421-159. http://dx.doi.org/10.1037/ipp0000033

Miranda, D., \& Rosabal-Coto, M. (1997). Patrones de socialización temprana (Informe de investigación). San José, Costa Rica: Instituto de Investigaciones Psicológicas, Universidad de Costa Rica. 
Moreno, W. (2003). Procesos de crianza de padres y madres guanacastecos y su incidencia en la formación de valores familiares (Tesis de maestría inédita). Universidad de Costa Rica, San José, Costa Rica.

Otto, H., y Keller, H. (Eds.) (2014). Different faces of Attachment. Cultural variations on a Universal Need. Cambridge, Reino Unido: Cambridge University Press.

Onwuegbuzie, A. J., \& Leech, N. L. (2006). Linking research questions to mixed methods data analysis procedures. The Qualitative Report, 11,(3), 474-498.

Poortinga, Y. H., \& Soudijn, K. (2002). Behavior-culture relationships and ontogenetic development. En H. Keller, Y. H. Poortinga, \& A. Scholmerich (Eds.), Between biology and cultura: Perspectives on ontogenetic development (pp. 320-340). Cambridge, United Kingdom: Cambridge University Press.

Rodríguez, L. (2010). Calidad de vida de niños con hemofilia en Costa Rica (Tesis de licenciatura inédita). Universidad de Costa Rica, San José, Costa Rica.

Rosabal-Coto, M. (2004). Parental belief systems, conflict resolution strategies, and cultural orientation in the mother-child interactive context: a comparative study of two Costa Rican samples (Disertación doctoral inédita). Universidad de Osnabrück, Osnabrück, República Federal de Alemania.

Rosabal-Coto, M. (2012). Creencias y prácticas de crianza: el estudio del parentaje en el contexto costarricense. Revista Costarricense de Psicología, 31(1-2), 65-100. Recuperado de http://rcps-cr.org/wp-content/themes/ rcps/descargas/2012/4-RCP-Vol.31-No1-2.pdf

Rübeling, H., Keller, H., Yovsi, R., Lenk, M., Schwarzer, S., \& Kühne, N. (2011). Children's Drawings of the Self as an Expression of Cultural Conceptions of the Self. Journal of Cross-Cultural Psychology, 42(3) 406-424. DOI: $10.1177 / 0022022110363475$

Sabogal, F., Marín, G., Otero-Sabogal, R., Vanoss, B., \& Pérez-Stable, E. (1987). Hispanic Familism and acculturation: What changes and what doesn't? Hispanic Journal of Behavioral Sciences, 9, 397-412.

Salgado, L. (2014). Creencias y prácticas de parentaje de una madre con diagnóstico trastorno afectivo bipolar y sus tres hijas (Tesis de licenciatura inédita). Universidad de Costa Rica, San José, Costa Rica.

Schwartz, S. (2007). The Applicability of Familism to Diverse Ethnic Groups: A Preliminary Stuy. The Journal of Social Psychology. 147(2), 101-118.

Seidl-de-Moura, M., Cruz de Carvalho, R., \& Vieria, M. (2013). Brazilian Mother's Cultural Models: Socialization for Autonomy and Relatedness. INTECH, 1-15. http://dx.doi.org/10.5772/57083

Sroufe, A., \& Waters, E. (1977). Attachment as an Organizational Construct. Child Development, 48, 1184-1199.

Steidel, A. G. L., \& Contreras, J. M. (2003). A new familism Scale for use with latino populations. Hispanic Journal of Behavioral Sciences, 23(1), 312-330. doi: 10.1177/0739986303256912

Triandis, H., Bontempo, R., Betancourt, H., Bond, M., Leung, K., Brenes, A.,... de Montmollin, G. (1986). The measurement of the etic aspects of individualism and collectivism across cultures. Australian Journal of Psychology, 38(3), 257-267. 
Triandis, H. C. (1988). Collectivism and individualism: A reconceptualization of a basic concept in cross-cultural psychology. En G. K. Verma, \& C. Bagley (Eds.), Personality, attitudes, and cognitions (pp. 60-95). Londres, Reino Unido. Macmillan.

van IJzendoorn, M. H., Palacios, J., Sonuga-Barke, E. J. S., Gunnar, M. R., Vorria, P., McCall, R. B.,... Juffer, F. (2011). I. Children in Institutional Care: Delayed Development and Resilience. Monographs of the Society for Research in Child Development, 76, 8-30. doi:10.1111/j.1540-5834.2011.00626.x

Van Leeuwen, K. G. (2000). Deficits in parenting skills as an indicator of behaviour problems with children and youth. Development of a screening instrument for the Flemish community. Manuscrito sin publicar, Departamento de Psicología, Universidad de Ghent, Reino de Bélgica.

Van Leeuwen, K. G., \& Vermulst, A. A. (2004). Some Psychometric Properties of the Ghent Parental Behavior Scale. European Journal of Psychological Assessment, 20(4), 283-298. http://dx.doi. org/10.1027/1015-5759.20.4.283

Whiting, B. B., \& Whiting, J. W. (1975). Children of six cultures: A psycho-cultural analysis. Cambridge: Harvard University Press.

Zamora Arrieta, M. (2016). Vivencia de niños y niñas con Cáncer entre los 6 y 12 años en sus Centros Educativos, su Percepción y Colaboración escuela-padres/madres de familia (Tesis de licenciatura inédita). Universidad de Costa Rica, San José, Costa Rica. 
Recibido: 29 de febrero de 2016 Revisión recibida: 18 de julio de 2017

Aceptado: 10 de agosto de 2017

Sobre los autores:

Esteban Durán-Delgado es licenciado en Psicología por la Universidad de Costa Rica y máster en Derechos Humanos de la UNED. Se desempeña como consultor social para agencias de cooperación internacional en temas de promoción y protección de derechos de las personas jóvenes en condición de vulnerabilidad e investigador independiente en psicología cultural del desarrollo. Cuenta con experiencia en gestión de la calidad académica, acreditación e investigación interna. Labora como docente de la carrera de psicología de la ULACIT. Posee publicaciones de orden técnico y académico en temas de derechos humanos, función familiar y desarrollo humano.

Mariano Rosabal-Coto es Doctor en Psicología del Desarrollo. Labora como profesor-investigador en la Universidad de Costa Rica (Investigador Instituto de Investigaciones Psicológicas y la Escuela de Psicología). Sus líneas de investigación son la Psicología cultural y la Psicología cultural del desarrollo. Ha desarrollado temas como la Psicología intercultural, el parentaje (crianza) y cultura, divorcio y parentalidad, cambio social y cambio intergeneracional y el apego, así como el familismo como rasgo culturalmente específico. Se destaca como autor de numerosas publicaciones, activo en varios grupos y redes de investigación internacionales. Se mantiene activo en el ejercicio profesional, como terapeuta, desde hace casi 30 años. 